\title{
Attitudes of employers to the mentally ill
}

\author{
Cressida Manning and Peter D. White
}

\begin{abstract}
Patients ofien aak poychiatists for advice on how to answer questions cbout their heolth, when seeking employment. They fear not being employed If they declare that they have sulfered from a mental illiness. The aftitudes of personnel directors of 200 randomly chosen public limited companies were mecsured. This confirmed signilicant reluctance, stigma and ignorance cbout employing and belleving the mentally III. Employers decided whether to employ someone by considering the lob description, the standard of previous work, whether the applicant was recelving treatment, provious time off sick, and the porticular Illiness sultiered. Those with depreselon were more likely to be employed than those with schizophrenia or atcohollem. The largest companies were signilicantly more likely to employ patients and were less likely to seek dismised than the smallest. Employers would welcome more information cbout mental ill heatth. Polential employees should approach large firms and seek treatiment.
\end{abstract}

Unemployment is one of the main difficulties faced by people trying to get back to a normal life after a mental illness (Herman \& Smith. 1989). Dightman \& Marks (1968) found that being in hospital a year previously and a lack of relevant work skills more or less guaranteed unemployment. That unemployment itself causes mental ill health produces a vicious circle that is hard to break out of (Lahelma. 1992).

People with affective disorders are more likely to be employed than those with alcoholism. People suffering from schizophrenia are the least likely to be employed (Bacani-Oropilla et al, 1991). Social rejection of the mentally ill is determined by previous personal experience of illness, perceived dangerousness, and age. Educational level may be particularly important in determining employment (Trute et al, 1989). Fortunately employers who specifically hire people with mental illness are motivated to re-integrate them into work and want more information about mental illness (Hubschmid \& Schaub. 1988).
From clinical experience, we believed that the stigma and ignorance of mental illness often determined the employment prospects of those who had been mentally ill. We therefore designed a study to examine the attitudes of employers to the employment of people who were or had been mentally ill.

\section{The study}

A 17-item questionnaire was designed to ask about attitudes to employing people who had been or were mentally ill. It was piloted with three personnel officers and the edited questionnaire was sent to a sample of 200 personnel directors of public limited companies, randomly selected from those registered with the Stock Exchange (Crawford, 1992). A reminder and second questionnaire were sent out after six weeks. The data were described and analysed using either the MannWhitney $U$ test or the $\chi^{2}$ test.

\section{Findings}

One hundred and twenty questionnaires were received, which correspond to a $60 \%$ response rate. Of these, 11 questionnaires were incomplete or inadequate and were therefore excluded.

Table 1 gives the main results. Half the employers would never or only occasionally employ someone currently unwell. This proportion was reduced to $28 \%$ when considering those previously unwell. Over half of employers would never/occasionally employ someone who was currently depressed. increasing to $66 \%$ when considering someone currently suffering from schizophrenia and $73 \%$ for those with alcoholism $\left(\chi^{2}=28.5,2\right.$ d.f., $P<0.001)$. The proportion never/occasionally employed fell by $13 \%$ if the employee was undertaking a "medically approved psychiatric drug treatment". 
Table 1. Percentage of employers who would recrult patients

\begin{tabular}{lllll}
\hline & \multicolumn{4}{l}{ Percentage responses $(n=109)$} \\
\cline { 2 - 5 } Health of candidate & Always/usually & Sometimes & Occasionally/never & Unsure \\
\hline Currently ill & 4 & 18 & 50 & 28 \\
Previously ill & 9 & 52 & 28 & 19 \\
Current depression & 9 & 18 & 54 & 19 \\
Current schizophrenia & 1 & 4 & 66 & 29 \\
Current alcoholism & 0 & 11 & 73 & 16 \\
\hline
\end{tabular}

Table 2. Factors considered in deciding offer of employment

\begin{tabular}{llccc}
\hline & \multicolumn{3}{c}{ Percentage responses (n=109) } & \\
\cline { 2 - 5 } Factor & Always/usually & Sometimes & Occasionally/never & Unsure \\
\hline Standard of previous work & 89 & 6 & 3 & 2 \\
Job description & 87 & 6 & 4 & 3 \\
Whether recelving treatment & 69 & 17 & 7 & 7 \\
Time off sick in previous year & 68 & 20 & 9 & 3 \\
Particular diagnosis & 64 & 15 & 12 & 9 \\
Age & 22 & 23 & 49 & 6 \\
Employees' attitudes & 16 & 31 & 42 & 11 \\
Marital status & 6 & 10 & 77 & 7 \\
Having children & 2 & 10 & 77 & 11 \\
Gender & 1 & 6 & 86 & 7 \\
\hline
\end{tabular}

To measure stigma we asked employers about whether they believed the medical diagnoses given in sick-notes. Eighty-two per cent of employers would usually believe someone being off sick for a physical illness, compared to only $63 \%$ of employers believing someone was genuinely ill with a psychological illness $\left(\chi^{2}=5.37,1\right.$ d.f., $\left.P=0.02\right)$. Twenty-three per cent would sometimes dismiss an employee for a previously undeclared mental illness, compared to $23 \%$ never doing so. Forty-nine per cent of employers would never dismiss someone developing a depressive lliness during employment, compared to $15 \%$ for alcoholism and $13 \%$ for schizophrenia ( $\chi^{2}=40.8,2$ d.f., $P<0.0001$ ).

Fifty-six per cent of employers considered that other employers were usually biased against employing those who were currently mentally ill. Twenty-nine per cent of employers thought that other employers were usually biased against those who had been previously mentally ill.

Table 2 shows the criteria that employers said they used to decide whether to employ someone who was or had been mentally ill. The most important factors were the job description, the standard of previous work, whether receiving treatment, and the time spent off sick in the previous year.
The size of the firm, as measured by the number of employees, had little influence on the employment of the mentally ill, when analysed by a median split. However, there were differences when we compared the largest $25 \%$ of companies with the smallest quartile. We found that the largest employers were significantly more likely to employ current mentally ill people (Mann-Whitney test: $P<0.01)$. The largest firms were also more likely to employ people with current alcohol problems $(P=0.02)$ and were less likely to dismiss them $(P=0.01)$.

\section{Comment}

We achieved a good response rate for an unsolicited random survey. We measured the bias of non-participation by asking respondents to judge the attitudes of other employers. These results were remarkably similar to their own attitudes. Fifty per cent of employers would never/occasionally employ the currently mentally ill, compared with $56 \%$ of other employers who were judged to be usually/always biased against employing the currently ill. This suggests that these results are representative of all public limited companies in this country. However, these results may not represent what employers do 
in practice. Personnel directors may also behave differently from other executives.

Most employers were cautious about employing people who were currently mentally ill, particularly those with schizophrenia or alcoholism. This replicates the findings of Bacani-Oropilla et al (1991), except that, in this study, alcoholism made a more negative impression.

The negative attitudes towards current or ex-patients may be related to previously unsuccessful employment. Against this, some employers prefer to employ a skilled patient more than an unskilled well person (Dightman \& Marks, 1968; Hubschmid \& Schaub, 1988). However, the strength of stigma and ignorance of mental illness was shown by the observation that employers were more likely to believe a sick-note declaring a physical rather than mental illness.

Only $13 \%$ of employers would usually dismiss an employee for having a mental illness which was previously undeclared. The majority of firms would not dismiss an employee for developing a depressive illness, but the attitude to alcoholism or schizophrenia was less liberal. The Employment Protection (Consolidation) Act (1978) does not discriminate between physical and mental ill health regarding dismissal on the grounds of incapability. Dismissal usually occurs for two reasons. First, the employee may be absent from work for considerable periods. Second, the illness may affect the employee's ability to perform his/her job satisfactorily or safely. The employer usually asks for a medical report. Using this information, the employer will decide the best course of action, balancing the needs of the employee and the firm (Croner, 1988). Options include deferral of a decision until the prognosis is more clear, transfer to other work within the firm, placement on a 'holding register' until recovered, early or medical retirement or dismissal.

Encouragingly, the most important criteria for recruitment were the work record, the job on offer, and previous sick leave, rather than the mental illness itself. Employment chances may be enhanced by being on a medically approved treatment programme.

What should potential employees do to enhance their chances of employment? Chances of employment are improved if the applicant is recovered, on a medically approved treatment programme, declaring a depressive illness, and stressing a previously good work record and minimal sick leave. Finally, it may be wise to seek employment from larger rather than smaller firms.

Many employers were 'unsure' in their replies. This may reflect ignorance about mental illness and its effect on work ability. Mental and occupational health professionals should provide appropriate information for employers. Mental health professionals should pay more attention to rehabilitation back to work (Lohr-Wiegmann, 1988). We should also fight prejudice by educational programmes, such as the Defeat Depression campaign (Sims, 1993), and working with the media (Scott, 1994) and employers.

\section{Acknowledgements}

The authors thank Fiona Ash, Janet Whelan, Anne Elliott, Marianne Woods and Dr Ruth Seifert for their help and advice, as well as the companies who participated in the study.

\section{References}

BACANI-OROPILA, T., LPPMANN, S., TUUY, E., et al (1991) Patients with mental disorders who work. Southern Medical Journal, 84, 323-327.

CRAWFORD's DIRECTORY OF CITY CONNBCTIONS (1992) London: Benn Business Information Services.

CRONER (1988) Croner's Employment Law. London: Croner Publications.

Dightman, C. R. \& MARKS, J. B. (1968) Employer attitudes toward the employment of the ex-psychlatric patient. Mental Hygiene, 62, 562-569.

Herman, N. J. \& SMrTh, C. M. (1989) Mental hospital depopulation in Canada: patient perspectives. Canadian Journal of Psychiatry, S4, 386-391.

HuBSCHMID, T. \& SCHAUB, M. (1988) Long-term psychiatric patients in the workplace. A survey of employers. Rehabilitation-Stuttgart, 27, 145-148.

LAHELMA, E. (1992) Unemployment and mental well-being: elaboration of the relationship. International Joumal of Health Services, 22, 261-274.

LOHR-WIEGMANN, U. (1988) Occupational rehabilitation of psychiatrically handicapped patients - concomitant help in employment. Rehabilitation-Stuttgart, 27. 69-76.

ScoTt, J. (1994) What the papers say. Psychiatric Bulletin. 18, 489-491.

Sims. A. (1993) The scar that is more than skin deep: the stigma of depression. Brttish Journal of General Practice. 43, 30-31.

TRuTE, B., TEFFt, B. \& Segnl., A. (1989) Social rejection of the mentally ill: a replication study of public attitude. Social Psychiatry and Psychiatric Epidemiology. 24. 69-76.

Cressida Manning, Medical student, The Royal London Medical Schooh and *Peter D. White, Senior Lecturer in Psychological Medicine, St. Barthlomew's Hospital Medical College, London ECIA 7BE

*Correspondence 